\title{
HIV/AIDS-related knowledge and behaviour of FET college students: Implications for sexual health promotion
}

\author{
C.G. MOODLEY AND J.S. PHILLIPS \\ Department of Physiotherapy, University of the Western Cape, Private Bag X17 \\ Bellville 7535, Cape Town, South Africa. E-Mail: jphillips@uwc.ac.za.
}

\begin{abstract}
The impact of the HIV/AIDS pandemic is mostly felt by adolescents as half of all new HIV/AIDS infections have occurred in people aged 15-24 years. Statistics show that campaigns implemented by the South African government have failed to bring about positive behavioural change among young people. The aim of this study was to determine the HIV/AIDS-related knowledge among students at a college and the association between knowledge, self-efficacy, self-concept in sexual practices. This study was conducted at a Further Education and Training College in Cape Town. Data were collected using self-administered questionnaires consisting of five sections including demographic information; sexual practices; knowledge of HIV/AIDS, levels of self-efficacy; and self-concept. Fifty four percent of the participants indicated no condom use when having sex, either by themselves or by a partner; $43 \%$ indicated that they had more than 2 sexual partners in the 12 months prior to the study. The odds that a person with higher HIV/AIDS knowledge will use a condom were 1.047 times greater than someone with less HIV/AIDS knowledge. The odd's ratio for self-efficacy indicates a positive relationship with the number of partners of an individual. The findings of the present study suggest adequate/high HIV/AIDS knowledge among the study sample. The study further highlights that for males, there is a greater likelihood that lower self-efficacy would predict more sexual partners in comparison to females. The results further suggest that although governmental organisations' efforts improved knowledge of HIV/AIDS, programmes avidly promoting self-efficacy for males should be implemented.
\end{abstract}

Keywords: HIV/AIDS-related knowledge, self-efficacy, self-concept, college students.

\section{How to cite this article:}

Moodley, C.G. \& Phillips, J.S. (2011). HIV/AIDS-related knowledge and behaviour of FET college students: Implications for sexual health promotion. African Journal for Physical, Health Education, Recreation and Dance, June (Supplement), 49-60.

\section{Introduction}

Research indicates that sub-Saharan Africa remains the region most affected by the HIV/AIDS pandemic. The National HIV and AIDS and STI Strategic Plan (NSP) for South Africa 2007-2011 estimated that in 2006, more than 63\% of HIV-infected people worldwide live in sub-Saharan Africa (NSP, 2007). This region accounts for $10 \%$ of the world's population, yet by $2005,24.5$ million of its people were infected with HIV/AIDS, including two million children younger than 15 years. There were about 2 million AIDS-related deaths in 2005 and 2.7 million new infections in 2005. The number of women with HIV in sub-Saharan 
Africa in 2005 numbered around 13.2 million, making up 59\% of the adult population (UNAIDS, 2008). South Africa too has been severely impacted by the HIV/AIDS pandemic and with the exception of India, South Africa has the largest number of people living with HIV/AIDS (Ngwena, 2003).

It is therefore evident that HIV/AIDS poses a major threat to South Africans, especially the youth, and that the future course of the HIV/AIDS pandemic depends on the behaviours adopted by young people early in their lives. The South African government has recognised the need for intervention prior to becoming infected. Therefore, one of the main aims of the NSP 2007-2011 strategy (NSP, 2007) is to reduce the rapid rate of new HIV/AIDS infections among people in the age group 15- 24 years. To this end, the South African government has implemented extensive anti-AIDS and health promotion campaigns to encourage responsible sexual practices amongst youth. However, given the above statistics these campaigns have failed to bring about positive behaviour change amongst young people (MacPhail \& Campbell, 2001; Hartell, 2005). Government efforts to implement participatory peer education approaches have also had limited impact on the AIDS epidemic, which continues to rise (MacPhail \& Campbell, 2001). Hartell (2005) has therefore advised that current promotion programmes need to be revised.

Research has indicated that being knowledgeable about the consequences of risky sexual behavior is not enough to bring about an expected behavioral change among the youth (Hartel, 2005; Erulkar, Bekshinska \& Cebekhulu, 2001). Sexual decision-making is an important factor that influences sexual practices. Gordon (1996) contends that both the knowledge of an individual and the ability to draw upon that knowledge affects decision-making. Furthermore, literature, although inconclusive, suggests that a link between intrapersonal factors such as self-concept and self-efficacy and sexual decision-making exists (Burns \& Dillon, 2005; Mashegoane, Moalusi, Ngoepe \& Peltzer, 2004; Langer, Warheit \& McDonald, 2001; Hollar \& Snizek, 1996).

The role of the educational institution in promoting sexual health is crucial. Ngwena (2003) contends that the education sector is in a favourable position to monitor new HIV/AIDS infections in children and young people. He contends that learners are in a process of learning sexual behaviour and are more inclined to be receptive to adopt safer sexual practices than adults who have already established their sexual practices. The Western Cape Education Department (WCED) and the FET colleges have recognised the challenges South Africans face regarding the HIV/AIDS pandemic and have attempted to address the needs of young people at FET institutions through the introduction of student support services. The Department of National Education in South Africa has also ratified a policy aimed at addressing HIV/AIDS in schools as well as other institutions of 
learning (The National Policy on HIV/AIDS for learners and educators in public schools, and students and educators in Further Education and Training Institutions, 1999).

However, there is a paucity of studies in the FET college sector investigating areas for intervention and identifying gaps in HIV/AIDS related knowledge, attitude and practices. Ferreira (2002) found that young people at FET colleges have insufficient knowledge, confidence and life skills to negotiate sexual issues, contraception, prevention of sexually transmitted infections (STI's) and HIV/AIDS. The baseline survey and needs assessment of FET colleges, conducted by the Planned Parenthood Association of South Africa (PPASA) (2004) among FET colleges in the Western Cape, attempted to investigate some of these aspects. The findings concur with Ferreira's (2002), that students are aware of the dangers of HIV/AIDS but that there are still gaps in HIV/AIDS related knowledge. A high number of respondents also reflected a sense of AIDS apathy. Thus, new and innovative messages and methods of training are required to communicate HIV/AIDS information.

The aim of this research was to establish the HIV/AIDS-related knowledge among students at a selected FET college in the Western Cape and the association between this knowledge, self-efficacy, self-concept and sexual practices.

\section{Methods}

Research design

A concurrent mixed model design was used for data collection. This design is a mixed methods design wherein there are two relatively independent phases: One consisting of the quantitative question (s), data collection and analysis techniques and the other comprising of qualitative question (s), data collection and analysis techniques. This paper is reporting on the quantitative phase of the study.

Study sample and location

The FET sector is a diverse and essential part of the South African education and training system. This sector is larger than the higher education and training (HET) sector in terms of the number of student enrolments and total expenditure. It also consists of a more diverse, and heterogeneous population (Ferreira, 2002). The FET sector is unique in that it provides training to students over a large age range from 16 to 60 years. This differs radically from the HET sector (universities) where most students commence their studies at age 18-19 years. Due to extensive government funding for the FET's new National Vocation 
Certificate (NCV) courses (which commenced January 2007) an even larger number of younger students will likely enrol at FET institutions in future.

The FET sector in the Western Cape comprises five colleges. The researchers deemed it appropriate to select the college with the largest number of students. Ethical clearance was obtained from the University of the Western Cape and permission to conduct the study from the Chief Executive Officer of the FET college and the Western Cape Education Department (WCED). The selected FET college consists of eight campuses with approximately 5000 students in the 18-24 year age group. One of these campuses had a very low number of students who indicated a willingness to participate in the study, which necessitated the exclusion of the campus. Therefore, the preliminary sampling frame consisted of 7 campuses with approximately 4000 students distributed among them. Using Yamane's formula (Israel, 1992), the calculated sample was approximately 370 participants. It was decided that it was appropriate to oversample as literature suggests that participation rates of lower than $50 \%$ are common. Of the students selected 1046 agreed to participate in the study. However, 492 questionnaires were found to be invalid and omitted from the study. The invalid questionnaires consisted of 76 respondents who did not fit into the age cohort 18-24 years and a further 416 respondents who did not fully complete the questionnaire (i.e. scales were incomplete). Incomplete questionnaires were discarded.

Thus, data from 554 participants were used in the final analysis. This sample consisted of 239 (43\%) males and 315 (57\%) females. The participants' ages ranged from 18 to 24 years, with a mean age of 20 years.

\section{Questionnaires}

Data were collected with self-administered questionnaires. The questionnaires were administered to students in groups in their various class settings. Written informed consent were obtained from the participants and their anonymity was ensured by not gathering personally identifiable data. Considering the sensitive nature of the questions and the possible emotional effect they might have, students were invited to contact the researcher to discuss questions or counselling needs. A psychologist was available for this purpose as well as student support staff. Data were collected over a period of six months.

The questionnaires consisted of five sections including demographic information; sexual practices (use of condoms, number of sexual partners); HIV/AIDS-related knowledge (HIV-KQ-18), levels of self-efficacy (The Sexual Risk Behaviour Belief and Self-efficacy Scale); and self-concept (AIDSCAP/WHO/CAPS Counselling and Test Efficacy Study questionnaire). 
All these scales were found reliable and yielded Chronbach's alpha coefficients ranging from 0.63 to 0.72 (Carey \& Schroder, 2002; Basen-Enquist et al., 1999).

\section{Data analysis}

Descriptive statistics were employed to summarize the demographic data, HIV/AIDS-related knowledge, self-efficacy and self-concept. The Chi-square test was used to ascertain if there was a significant relationship between gender and sexual practices reflected by condom use and the number of sexual partners in the 12 months prior to participation in the study. Furthermore, a Hotteling's $\mathrm{T}^{2}$-test was conducted to establish if there was a significant difference between males and females for the predictor variables of HIV/AIDS-related knowledge, self-concept and self-efficacy. Two steps of analysis were performed to investigate the relationship between HIV/AIDS knowledge, self-efficacy, selfconcept and sexual practices. The first step was to investigate multicollinearity to ascertain if the variables were ideal to perform a multivariate analysis. The second step was to sequentially conduct various models by means of logistic regression analysis attempting to determine which model most accurately predicted sexual practices identified by condom use and number of partners in the 12 months prior to participation in the study. Logistic regression was performed to establish whether there were any relationships amongst the predictor variables (HIV/AIDS-related knowledge, self-efficacy, self-concept) and the criterion variable (sexual practices in terms of condom use and number of sexual partners in the 12 months prior to the study) for the sample. In order to describe the effect of gender on the relationship between HIV/AIDS-related knowledge, self-efficacy, self-concept and sexual practice involved two steps of analysis. The first step was to sequentially conduct various models by means of logistic regression analysis to determine which model most accurately predicted sexual practices identified by condom use and number of partners in the 12 months preceding the study. Logistic regression analysis was conducted to establish the relationship between HIV/AIDS-related knowledge, self-efficacy, self-concept and sexual practices for the sample.

\section{Results}

More than half (54.5\%) of the participants indicated that condom was not used when having sex, either by themselves or by a partner and significantly more males $(70 \%)$ than females $(43 \%)$ reported no condom use when engaging in sex $(p<0.05)$. Furthermore, $43 \%$ of the participants indicated that they had two or more sexual partners in the 12 months prior to the study, of which significantly more males $(62 \%)$ than females $(28 \%)$. The mean score for HIV/AIDS-related knowledge for the study sample was $57.80(\mathrm{SD}=5.51)$ indicating that the level of HIV/AIDS-related knowledge were above average. 


\section{Moodley and Phillips}

The results exploring whether there was a difference between males and females on the predictor variables of HIV/AIDS-related knowledge, self-concept and self-efficacy, are summarized in Table 1 . The post hoc t-tests indicate that males (16.18) had significantly lower self-efficacy than females $(t=13.92 ; p<0.05)$. This scale was constructed in such a manner that a low score denoted high selfefficacy and a high score denoted low self-efficacy. No significant differences were found for HIV/AIDS-related knowledge and self-concept between males and females $(\mathrm{p}>0.05)$.

Table 1: Hotelling's $\mathrm{T}^{2}$ - test results for the sample $(\mathrm{n}=554)$

\begin{tabular}{lccccc}
\hline & Male $(\mathrm{n}=239)$ & \multicolumn{2}{c}{ Female $(\mathrm{n}=315)$} & & \\
\cline { 2 - 4 } Variable & Mean & Mean & df & F & p-value \\
\hline \multirow{2}{*}{ Self-efficacy } & 16.18 & 13.92 & 1 & 41.60 & $0.00^{*}$ \\
& $(4.22)$ & $(3.97)$ & & & \\
HIV/AIDS knowledge & 57.70 & 57.87 & 1 & 0.13 & 0.72 \\
\multirow{2}{*}{ Self-concept } & $(5.84)$ & $(5.25)$ & & & \\
& 14.04 & 13.93 & 1 & 0.14 & 0.71 \\
\hline
\end{tabular}

$\mathrm{T} 2=0.078 ; \mathrm{F}(3,550)=14.35 \mathrm{p}<0.00 ; * \mathrm{p}<.05$

Three-predictor logistic model was fitted to the data to test the research hypothesis regarding the likelihood that HIV/AIDS-related knowledge, selfefficacy and self-concept would predict sexual practices (condom use and number of sexual partners in the 12 months prior to the study). The results indicates that the -2 times the $\log$ likelihood $(-2 L L)$ value was reduced from the base (intercept only) model at 730.144 , to the full model (the model including all three predictors) at 721.102 , a reduction of 9.042. The Chi-square value was significant suggesting that the overall model was significantly different from the null model of the intercept only. This indicates that the predictors, as a set, reliably predict condom use. An examination of the Wald statistics reveals that only the HIV/AIDS-related knowledge variable was significantly positive suggesting that having HIV/AIDS-related knowledge could predict condom use. The odds that a person with higher HIV/AIDS-related knowledge will use a condom are 1.047 times greater than someone with less HIV/AIDS-related knowledge by one unit.

Furthermore, the results indicates that the -2 times the log likelihood (-2LL) value was reduced from the base (intercept only) model, to the full model (the model including all three predictors). The Chi-square statistic of the model was examined to determine if the overall model was statistically significant. The results revealed that the Chi-square value was significant suggesting that the full 
model was highly significantly different from the null model of the intercept only. This indicates that the predictors as a set, predict whether a person would have $>2$ or $<2$ sexual partners in a twelve month period preceding the study.

Table 2: Wald statistics for the Model: condom use

\begin{tabular}{lllll}
\hline $\mathrm{N}=554$ & Constant & HIV/AIDS knowledge & Self-efficacy & Self-concept \\
\hline Wald's Chi-Square & 5.723 & 7.925 & 1.112 & .026 \\
p-level & $.017^{*}$ & $.005^{*}$ & .292 & .872 \\
Odd's ratio (unit ch) & .081 & 1.047 & 1.023 & 1.005 \\
$-95 \%$ CI & & 1.014 & .980 & .950 \\
$+95 \%$ CI & & 1.081 & 1.069 & 1.062 \\
\hline
\end{tabular}

Table 3: Wald statistics for the Model: Multiple sexual partners

\begin{tabular}{lllll}
\hline $\mathrm{N}=554$ & Constant & HIV/AIDS knowledge & Self-efficacy & Self-concept \\
\hline Wald's Chi-Square & 1.474 & .408 & 31.104 & .752 \\
p-level & .225 & .523 & $.000^{*}$ & .386 \\
Odd's ratio (unit ch) & .277 & .990 & 1.139 & .976 \\
$-95 \%$ CI & & .959 & 1.088 & .923 \\
$+95 \%$ CI & & 1.022 & 1.192 & 1.031 \\
\hline$* 0.05$ & & &
\end{tabular}

An examination of the Wald statistics revealed that only self-efficacy was highly significantly positive, suggesting that an increase in an individual's self-efficacy would predict an increase in the number of partners an individual would have. Furthermore, the odd's ratio value for self-efficacy indicates a positive relationship with the number of partners of an individual. This means that, if an individual's self-efficacy score increases by one unit, the odds of having more than one sexual partner will increase by 1.139. Thus, a person with lower selfefficacy has an increased probability of having more than one sexual partner.

A predictor logistic model was fitted to the data to test the research hypothesis regarding the likelihood that gender would affect the relationship between HIV/AIDS-related knowledge, self-efficacy, self-concept and sexual practices (condom use and number of sexual partners in the 12 months prior to the study). The Chi-square value suggests that the overall full model was highly significantly different from the null model of the intercept only. An examination of the Wald statistics revealed that both knowledge of HIV/AIDS and gender were significantly positive, suggesting that an increase in an individual's HIV/AIDS-related knowledge would predict an increase in the use of a condom by an individual (Table 4). Furthermore, the gender of the participant affected the relationship between HIV/AIDS-related knowledge and condom use. 


\section{Moodley and Phillips}

The odds ratio value for HIV/AIDS indicates a potential positive relationship with gender. Thus, HIV/AIDS-related knowledge remained a significant predictor of condom use even though gender was added to the model. The odds ratio value for HIV/AIDS-related knowledge indicates that with 1 unit increase in HIV/AIDSrelated knowledge the odds of a person using condoms increases with 1.048. Furthermore, the results indicated that the odds of a male using a condom increased by 1.762 .

Table 4: Wald statistics for the Model: Condom use (gender)

\begin{tabular}{llllll}
\hline $\mathrm{N}=554$ & Constant & $\begin{array}{l}\text { HIV/AIDS } \\
\text { knowledge }\end{array}$ & Self-efficacy & Self-concept & Gender \\
\hline Wald's Chi-Square & 5.963 & 8.070 & .046 & .100 & 8.868 \\
p-level & $.015^{*}$ & $.005^{*}$ & .831 & .752 & $.003^{*}$ \\
Odd's ratio (unit ch) & .076 & 1.048 & 1.005 & 1.009 & 1.762 \\
$-95 \%$ CL & & 1.015 & .961 & .954 & 1.214 \\
$+95 \%$ CL & & 1.082 & 1.051 & 1.067 & 2.558 \\
\hline
\end{tabular}

$\mathrm{p}<0.05$

Analyses were undertaken to determine which of the predictor variables (HIV/AIDS-related knowledge, self-efficacy, self-concept and gender) best predicted multiple sexual partners. An examination of the Wald statistics revealed that self-efficacy has a significant relationship with multiple sexual partners suggesting that an increase in an individual's self-efficacy score (thus lower self efficacy) would predict an increase in the number of sexual partners an individual would have had in the twelve month period prior to the study (Table 5). This means that with each unit increase in the self-efficacy score the odds increase of having more than one partner by 1.099. Therefore, if the individual has low self-efficacy the possibility of having more than one sexual partner increases. Furthermore, the results indicate if you are a male, the odds of having more than one partner is 3.561 times higher than if you are female. Thus, self-efficacy remained a significant predictor with gender added to the model, but gender also affected the prediction significantly.

Table 5: Wald statistics for the Model: Multiple sexual partners in the 12 months preceding the study (gender)

\begin{tabular}{llllll}
\hline $\mathrm{N}=554$ & Constant & $\begin{array}{l}\text { HIV/AIDS } \\
\text { knowledge }\end{array}$ & Self-efficacy & Self-concept & Gender \\
\hline Wald's Chi-Square & 1.553 & .482 & 15.483 & .289 & 45.285 \\
p-level & .213 & .487 & $.000^{*}$ & .591 & .000 \\
Odd's ratio (unit ch) & .254 & .988 & 1.099 & .984 & 3.561 \\
$-95 \%$ CI & & .956 & 1.049 & .928 & 2.460 \\
$+95 \%$ CI & & 1.022 & 1.152 & 1.043 & 5.154 \\
\hline $\mathrm{p}<0.05$ & & & &
\end{tabular}




\section{Discussion}

Young people worldwide are increasingly affected by HIV/AIDS with those most affected living in Sub-Saharan Africa (Bonkole et al., 2007). International research suggests that sufficient knowledge around HIV is a necessary first step towards reducing its incidence, though inadequate in the prevention of the disease (Wong et al., 2008). Several local and international studies (Pettifor et al., 2005; UNFPA, 2003) have investigated HIV/AIDS knowledge among youth but revealed inconsistent findings. Research relating specifically to HIV/AIDS knowledge among college students has consistently indicated that knowledge alone does not predict safe sexual practices (Opt \& Loffredo, 2004).

The findings of this study suggest that there is high HIV/AIDS-related knowledge among this sample of FET college students. This suggests that the concerted efforts by governmental organisations have had a positive impact on promoting of HIV/AIDS-related knowledge. However, it is debatable whether improved knowledge has led to safer sexual practices among South African youth (Erulkar et al., 2001). Phillips and Malcolm (2006) assert that the biggest obstacle to behavioural change is socially supported beliefs and that knowledge should be imparted to the entire at- risk group and larger communities in which the group is embedded. The results of the current study suggest that although knowledge of the risk of HIV/AIDS may be an important element in condom use promotion campaigns, efforts should be made to understand and explore the complex structure of sexuality in adolescence. Efforts should also be made to expand on the traditional belief that sexual behaviour is the consequence of rational decisions based on knowledge only (Sayles et al., 2006).

Some of the risk factors affecting sexual and reproductive health include unprotected sexual intercourse and multiple sexual partners. These risk factors place people at risk for HIV infection, STI's and unplanned pregnancy. This study shows that college students risk their sexual health by having multiple sexual partners and engaging in unprotected sex. The results also showed a higher percentage of males reporting multiple sexual partners in the study, similar to other studies among students in higher education (National Communication survey on HIV/AIDS (NCS), 2009). Lefkowitz and Gillen (2005) suggested that it is crucial to acknowledge and understand gender differences, but they should not be overstated. Pettifor et al. (2004) contends that it is common to have a difference in the reported number of partners among males and females. They further stated that the possible justification for this could be that males over-report and females under-report sex-related information and that these gender differences may simply reflect differences in reporting. The findings imply that sexual and reproductive health programmes should specifically target both sexes during adolescence and not solely focus on females 
as it is often the case. The results of the study also highlights that health promotion programmes should assist young men to find novel ways to express themselves and to change traditional gender roles. The study further shows that for males there is a greater likelihood that lower self-efficacy would predict more sexual partners in comparison to females. Programmes avidly promoting selfefficacy for males should thus be implemented.

\section{Conclusion}

This study indicates that more than $50 \%$ of the sample did not use condoms when having sexual intercourse in the twelve months prior to the study. Considering the severity of the HIV/AIDS pandemic, these findings are alarming and show that the participants engaged in sexual risk taking behaviour despite possessing knowledge about the transmission of HIV. This also highlights the false belief of invulnerability as demonstrated in the lack or reluctance of participants to use condoms and relates to the typical behaviour patterns of individuals in the emerging adult phase of development (Arnett, 2000). A possible intervention could be providing professional and youth friendly sex education and promotion services at campuses of FET colleges.

\section{References}

Arnett, J.J. (2000). Emerging adulthood: A theory of development from the late teens through the twenties. American Psychology, 1(55), 469-480.

Basen-Enquist, K., Mâsse, L.C., Coyle, K., Kirby, D., Parcel, G.S., Banspach, S., \& Nodora, J. (1999). Validity of scales measuring the psychosocial determinants of HIV/STD-related risk behaviour in adolescents. Health Education Research Theory\& Practice, 14(1), 25-38.

Bonkole, A., Ahmed, F.H., Neema, S., Ouedraogo, S. \& Konyoni, S. (2007). Knowledge of correct condom use and consistency of use among adolescents in four countries in Sub-Saharan African. African Journal of Reproductive Health, 11 (3), 197-220.

Burns, M.J., \& Dillon, F.R. (2005). AIDS health locus of control, self-efficacy for safer sexual practices, and future time orientation as predictors of condom use in African American college students. Journal of Black Psychology, 31(2), 172-188.

Carey, M.P. \& Schroder, K.E. (2002). Development and psychometric evaluation of the brief HIV knowledge questionnaire. AIDS Education and Prevention, 14, 172-182.

Erulkar, A.S., Bekshinska, M. \& Cebekhulu, Q. (2001). An assessment of youth centres in South Africa. Summaries, 24 November 2001.

Ferreira, S.L. (2002). The design, implementation and evaluation of student support and development services in the further education and training colleges in South Africa. Unpublished thesis. University of the Western Cape, South Africa. 
Gordon, C.P. (1996). Adolescent decision-making: A broadly based theory and its application to the prevention of early pregnancy. Journal of Adolescence, 3(123), 561-584.

Hartell, C.G. (2005). HIV/AIDS in South Africa: A review of sexual behaviour among adolescents. Journal of Adolescence, 40 (157), 171-181.

Hollar, D., \& Snizek, W. (1996). The influences of knowledge of HIV/AIDS and self-esteem on the sexual practices of college students. Social Behavior and Personality, 24(1), 75-86.

Israel, G.D. (1992). Determining sample size. University of Florida. Available at: http://edis.ifs.ufl-edu/PD006. Retrieved February 12, 2010.

Langer, L., Warheit, G., \& McDonald, L. (2001). Correlates and predictors of risky sexual practices among a multi-racial/ethnic sample of university students. Social Behavior and Personality, 29(2), 133-144.

Lefkowitz, E.S. \& Gillen, M.M. (2005). Sex is just a normal part of life: Sexuality in emerging adulthood. In J.J. Arnet \& J.L. Tanner (Eds.), Emerging adults in America: Coming of age in the $21^{\text {st }}$ century (pp. 235-255). Washington, DC: American Psychological Association.

Mac Phail,C. \& Campbell, C. (2001). 'I think condoms are good, but aai, I hate those things ' condom use among adolescence and young people in a South African township. Journal of Social Science and Medicine, 52, 1613-1627.

Mashegoane, S., Moalusi, K.P., Ngoepe, M.A. \& Peltzer, K. (2004). The prediction of condom use intention among South African university students. Psychological Reports, 95(12), 407-411.

McNair, L., Carter, J. \& Williams, M. (1998). Self-esteem, gender, and alcohol use: Relationships with HIV risk perception and behaviors in college students. Journal of Sex and Marital Therapy, 24, 29-36.

National Communication survey on HIV/AIDS (NCS). (2009). Available at: http://www.jhhesa.org.za/ Accessed January 6, 2010. National HIV \& AIDS and STI Strategic Plan for South Africa 2007-2011. Draft 9 (NSP, 2007-2011, 2007).

Ngwena, C. (2003). AIDS in schools: A human rights perspective on parameters for sexuality education. Acta Academia, 35(2), 184-204.

Opt, S.K. \& Loffredo, D.A. (2004). College students and HIV/AIDS: More insights on knowledge, testing and sexual practices. Journal of Psychology, 138, 389-402.

Perkel, A.K. (1992). Psychosocial variables in the transmission of AIDS. Unpublished Mater's thesis, University of the Western Cape, Cape Town, South Africa.

Pettifor, A.E., Rees, H.V., Kleinschmidt, I., Steffenson, A.E., MacPhail, C., HlongwaMadikizela, L., Vermaak, K. \& Padian, N.S. (2005). Young people's sexual health in South Africa: HIV prevalence and sexual behaviours from a nationally representative household survey (Epidemiology and Social). AIDS, 19(14), 1525-1534.

Pettifor, A.E., Measham, D.M., Rees, H.V. \& Padian, N.S. (2004). Sexual Power and HIV Risk, South Africa. Conference Report: International conference on Women and Infectious Diseases. Journal of Emerging Infectious Diseases, 10(11), 1996-2004. 
Phillips, J.S. \& Malcolm, C. (2006). Sexual risk behaviour among adolescent school girls in a local community in the Western Cape. African Journal for Physical Health, Recreation and Dance, 12(4), 426-437.

Planned Parenthood Association of South Africa (PPASA) (2004). FET colleges: Baseline Needs Assessment: Final Report. Compiler: Karen Webber.

Sayles, J.N., Pettifor, A., Wong, M.D., MacPhail, C., Lee, S.J., Hendriksen, E., Rees, H.V. \& Coates, T. (2006). Factors Associated with self-efficacy for condom use and sexual negotiation among South African youth. Journal of Acquired Immune Deficiency Syndrome, 43(2), 226-233.

Seal, A., Minichiello, V. \& Omodei, M. (1997). Young women's sexual risk taking behaviour: Re-visiting the influences of sexual self-efficacy and sexual self-esteem. International Journal of STD \& AIDS, 8 (3): 159-165.

Seal, A., Minichiello, V. \& Omodei, M. (1997). Young women's sexual risk taking behaviour: Re-visiting the influences of sexual self-efficacy and sexual self-esteem. International Journal of STD \& AIDS, 8 (3), 159-165.

Shisana O., Rehle T., Simbayi L.C., Zuma K, Jooste S, Pillay-van-Wyk V, Mbelle N., Van Zyl J., Parker W., Zungu N.P., Pezi S. \& the SABSSM III Implementation Team (2009). South African national HIV prevalence, incidence, behaviour and communication survey 2008: A turning tide among teenagers? Cape Town: HSRC Press.

The National Policy on HIV/AIDS for learners and educators in public schools, and students and educators in Further Education and Training Institutions. (1999). Department of Education, 410, 20372 .

United Nations \& AIDS (UNAIDS). (2008). Report on the global AIDS Epidemic. Geneva: UNAIDS.

United Nations Population Fund (UNFPA) (2003). State of the world population. Investing in adolescents' health rights. News feature, New York.

Wong, L., Chin, C., Low, W. \& Jaafar, N. (2008). HIV/AIDS-Related Knowledge among Malaysian Young Adults: Findings from a Nationwide Survey. Medscape Journal of Medicine, 10 (6), 148, DOI: 10.1186/1758-2652-10-6-148. 